\title{
Article \\ Mathematical Modeling and Computer-Aided Simulation of the Acoustic Response for Cracked Steel Specimens
}

\author{
Arbab Akbar $\left(\mathbb{D}\right.$, Muhammad Ahmad Kamran ${ }^{(0)}$, Jeesu Kim * $*$ and Myung Yung Jeong * \\ Department of Cogno-Mechatronics Engineering, Pusan National University, Busan 46241, Korea; \\ arbab@pusan.ac.kr (A.A.); malik@pusan.ac.kr (M.A.K.) \\ * Correspondence: jeesukim@pusan.ac.kr (J.K.); myjeong@pusan.ac.kr (M.Y.J.)
}

check for updates

Citation: Akbar, A.; Kamran, M.A.; Kim, J.; Jeong, M.Y. Mathematical Modeling and Computer-Aided Simulation of the Acoustic Response for Cracked Steel Specimens. Appl. Sci. 2021, 11, 7699. https://doi.org/ 10.3390/app11167699

Academic Editor: Mohammed Chadli

Received: 27 July 2021

Accepted: 18 August 2021

Published: 21 August 2021

Publisher's Note: MDPI stays neutral with regard to jurisdictional claims in published maps and institutional affiliations.

Copyright: (c) 2021 by the authors. Licensee MDPI, Basel, Switzerland. This article is an open access article distributed under the terms and conditions of the Creative Commons Attribution (CC BY) license (https:// creativecommons.org/licenses/by/ $4.0 /)$.

\begin{abstract}
Photoacoustic imaging (PAI) is an emerging nondestructive testing technique to evaluate ever-growing steel products and structures for safety and reliability. In this study, we have analyzed steel material with inbuilt cracks using computer-aided numerical simulations, imitating the PAI methodology. Cracks are introduced in a steel cylinder along three axes at different locations, and then a finite element method simulation in Abaqus software is performed to generate an acoustic wave and read it back at sensing locations after passing through the crack. The data are observed, analyzed, and modeled using the composite sine wave data fitting modeling technique. Afterwards, the Nelder-Mead simplex method is used to optimize the parameters of the model. It is concluded that with the change in the crack location, there is a change in the model parameters such as amplitude and frequencies. Results for cracks at seven different locations along each of the three axes are added, and listed in tabular form to present an analysis and comparison of the changes in the modeled parameters with respect to these crack locations.
\end{abstract}

Keywords: nondestructive testing; structural health monitoring; photoacoustic imaging; Abaqus Simulation; optical imaging

\section{Introduction}

Stainless-steels are an important class of alloys considering their plentiful applications in daily life. The durability and anticorrosive properties of stainless-steel attract huge budget allocation by countries such as China in its large-scale production and consumption [1]. It is one of the most widely used materials in producing items ranging from cooking utensils [2] to high-rise buildings [3], from small toys to huge air crafts, and from small containers to huge ships and even space vehicles [4]. Application areas of steel include construction, transportation, nuclear and chemical industries, medical equipment, communication and computing devices, roads and bridges, etc. [5,6]. In fact, its omnipresence in our daily life makes it difficult to set out all concomitant applications. Due to its widespread applications, it is direly important to ensure its good structural integrity at the time of manufacturing and with the passage of time to cater to aging effects. Micro-cracks and defects in steel due to mechanical strain or environmental conditions have always attracted researchers to devise reliable and quick methods to achieve timely, successful, and precise detection [7-12]. In a report card for American infrastructure 2021, the American Society of Civil Engineers (ASCE) compared the condition of different infrastructures in the USA for several years and estimated the cost of upgrading them to safe limits for current and future usage. Most of these infrastructures incorporate extensive use of steel, including dams, bridges, ports, roads, rail, and aviation, and were found to not be in good condition and require high-cost renovation [13].

In comparison to destructive techniques for defect monitoring, nondestructive testing (NDT) techniques have several benefits: good sensitivity, cost-effectiveness, sample usability, possibility for non-contact, and easy setup, which requires no transducer arrangements, possibility of deployment in harsh and sensitive environments, broad sensing range, 
and capability to test huge, moving, and remote targets [14-16]. Among NDT methods, visual inspection is the oldest method for defect analysis and is currently widely used. Currently, due to technological advancements, these methods have a magnification setup or an electronic visual sensor [17,18]. This technological advancement has enabled humans to develop state-of-the-art robotic systems that incorporate vision sensors (digital cameras, lenses, and lights) to continuously acquire visual details in hazardous environments [19]. Such vision-based visual inspection techniques have also proven their benefit in civil structure crack detection and amazing characteristics of automatic collection and analysis of visual data [20].

Visual inspection often helps to perform routine inspection and maintenance of bridges, although it is time-consuming, requires significant expert personnel, and is consequently expensive. Vibration-based NDT damage detection techniques have been used by engineers and researchers, particularly in the aerospace and offshore oil industries, since the late 1970s [21]. Using these techniques, damage sizes and locations are estimated by comparing the modal data of an intact structure and a damaged structure [22]. Common parameters in vibration-based methods are natural frequency and displacement/strain mode shape.

However, vibration-based techniques are limited due to their low sensitivity and accuracy, especially when the damage size is small. In industry, one of the most commonly observed material degradation mechanisms due to prolonged cyclic stress is fatigue. With the passage of time, this phenomenon reduces the effective service life of engineering structures and components [23]. Fatigue causes almost $90 \%$ of industrial component failures that suddenly occur without warning [24]. Therefore, NDT of industrial structures has always inspired researchers to innovate methods for more effective and precise results [25]. In the past, fatigue measurements in metallic components have been performed by scanning electron microscopy (SEM) [26], ultrasonic waves [27], acoustic emissions [28], X-rays [29], etc. Although these methods have been extensively used in the past, each method has its own pros and cons, such as expensive setup cost, requirement of physical contact, and need for experienced manpower. Therefore, improvement in existing methods and/or development of a new technique for a specified purpose has attracted several research groups. Recently, advanced signal processing techniques, e.g., blind feature extraction, sparse representation classification, artificial intelligence algorithms, and compressive sensing algorithms, have been successfully applied in structural health monitoring and damage detection, especially for rotating bodies such as bearings [30] and huge structures such as bridges [31]. Guided wave propagation-based NDT diagnostics are popular because they enable inspection of large areas in a single measurement, but the main limitation is the requirement of sensor installation at the target [32]. Conventional NDT methods for conductive materials include eddy current testing (ECT) to detect flaws [33]. Single-frequency sinusoidal excitation as a function of changes in voltage, impedance, or phase enables the detection of defects or flaws. Due to limited depths of penetration and complexity in signal analysis, ECT is limited to fewer applications. Studies have shown the possibility to apply wavelet transform for defect detection in steel on a laboratory scale [34].

In NDT, there is a powerful technique called photoacoustic imaging (PAI) [35], which combines the high-resolution advantages of optical imaging techniques [36] and good penetration capabilities of ultrasound [37]. PAI applications cover a broad spectrum, from biomedical imaging [38] to material composition problems, and even imaging deep-sea environments [39]. The working principle of PAI is based on the multi-physics phenomenon that occurs in the target material. First, the target is hit by an excitation laser, and thermal expansion occurs inside the material depending on the material properties and energy of the incident pulse laser beam. The phenomenon is described in Figure 1. 


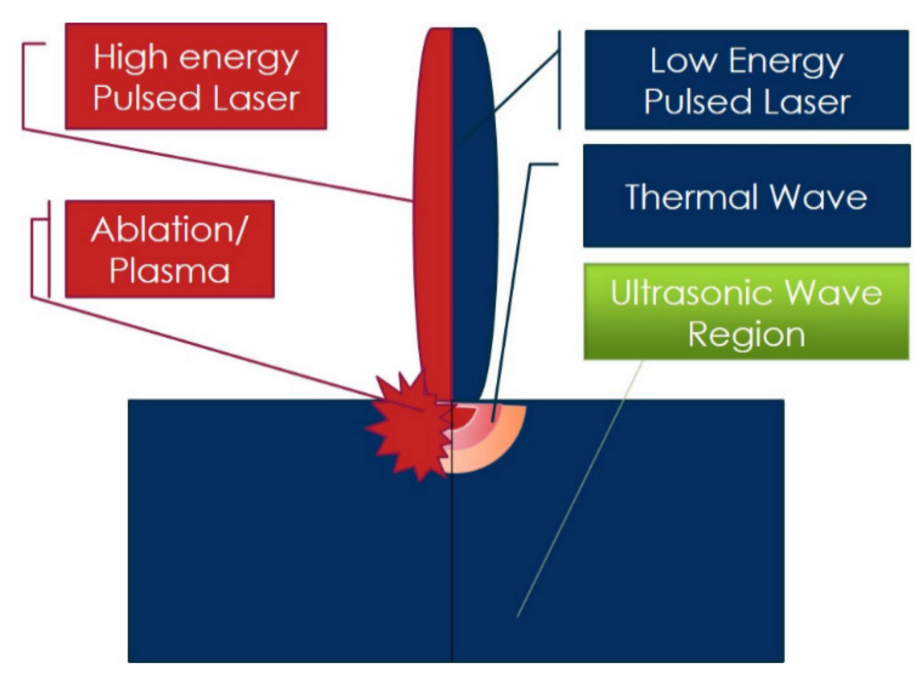

Figure 1. Effects of different energies of the excitation laser on the target material causing thermal expansion or ablation/melting.

In this study, simulations are performed on a steel pipe to study the wave signal that reaches the sensing point. The signal for a wave traveling through the pipe with no defect is saved for reference and comparison. The traveling wave may experience damage in the pipe at one of the several predetermined locations. The wave parameters, which reach the sensing point, are analyzed for an in-depth knowledge about the behavior of the wave in different crack conditions. These differences provide an indication for damage presence inside the target, which can be further worked out to localize the damage location in the future.

\section{Materials and Methods}

In this study, the propagation of acoustic waves through a steel pipe is studied. Abaqus/CAE (Dassault Systèmes, Vélizy-Villacoublay, France) is used to develop the 3D model and its simulation.

\subsection{System Mechanism}

In this study, a mechanism to detect cracks in steel material is proposed, and the results of stating different wave parameters are analyzed to point out differences based on crack locations. The study is strengthened by multi-physics finite element model (FEM) simulations (performed using Abaqus software) of the system.

There are three main blocks of a photoacoustic system: an excitation laser system, a sensing laser system, and a control system, as depicted in Figure 2. As the name suggests, the control unit, which consists of a computer system, is responsible for the arbitration process for excitation and sensing systems to simultaneously start their tasks. The excitation system comprises of a pulsed laser and is responsible for providing the target material with a precise amount of thermal energy to initiate the thermal expansion phenomenon. This excitation generates acoustic waves in the material, which travel through the length of the material. Then, the sensing system measures the acoustic waves at designated sensing points. Data are sent to the control unit PC for image generation and further analysis. If the energy of the excitation laser is too high for the target material, then ablation, melting, or plasma formation can occur, which are not suitable in the current research scenario. Therefore, we are interested in designing the input laser power that produces thermal expansion, which results in acoustic waves due to pressure differences in the surroundings. Finally, the sensing laser measures these acoustic waves to estimate the composition of the target object, and the observed data are used to generate images for further analysis. 


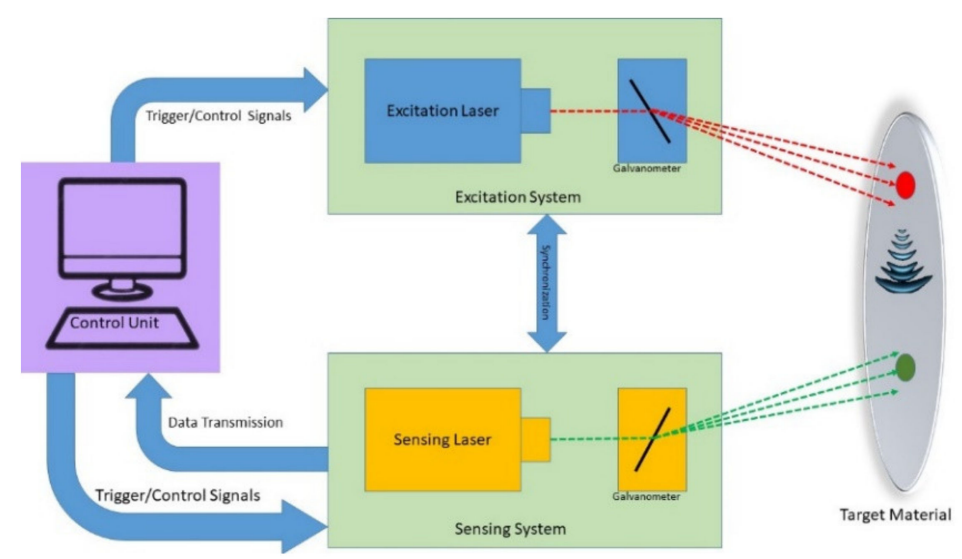

Figure 2. Block diagram of a photoacoustic imaging system.

\subsection{Simulation Setup}

The underlying aim of the study is to efficiently and precisely locate any defect or damage, such as cracks in steel, using simulation, which imitates the photoacoustic imaging technique. The simulation setup is shown in Figure 3. The target object is a steel cylindrical pipe with a base radius of $10 \mathrm{~mm}$, a thickness of $1 \mathrm{~mm}$, and an axis length of $100 \mathrm{~mm}$, as depicted in Figure 3a. A crack is formed in the center of the steel rod. The edge diagram of the steel pipe under observation and the corresponding crack are shown in Figure 3b. Figure $3 \mathrm{c}$ shows the cross-sectional view of the steel pipe with global origin. The radii of the inner and outer steel surfaces are 9 and $10 \mathrm{~mm}$, respectively. The crack is $2 \mathrm{~mm}$ wide and $15 \mathrm{~mm}$ long, as displayed in the two-dimensional surface view in Figure 3d. The mesh size is an important parameter in FEM simulations; generally, a fine mesh and a smaller time step result in more accurate results, but are associated with high processing costs in terms of computing time and resources. To obtain adequate accuracy and high efficiency, the maximum element size and time step are adopted according to Reference [40], where they can be mathematically expressed as:

$$
\Delta I=\frac{\lambda_{\min }}{20},
$$

where $\Delta I$ is the element size and $\lambda_{\min }$ is the minimum wavelength of the propagating wave. The simulation time step is defined as:

$$
\Delta t=\frac{1}{20 f_{\max }},
$$

where $\Delta t$ is the simulation time step and $f_{\max }$ is the highest frequency of interest. Table 1 lists the elastic and mechanical properties of the steel for the simulation settings. Abaqus CAE is utilized to develop the 3D model of the setup, and cracks are localized to verify the proposed technique. A mechanical force at the excitation point actuates acoustic waves to imitate the photoacoustic imaging modality and applies a load in the simulation. At the designated sensing points, the generated acoustic waves that travel through the pipe are measured. Data at sensing points are logged and saved for further analyses. The scheme of this study is to develop a numerical model of the data acquired through the PAI setup of steel pipes in pristine conditions with cracks at different locations. The key feature of this idea is to generate ample responses of pipes with known crack locations to approximate the entire pipe by a combination of these responses. Then, when a new response with an unknown damage location is presented to the designed model, it estimates the crack location by interpolating the best match of the data with the existing information. 


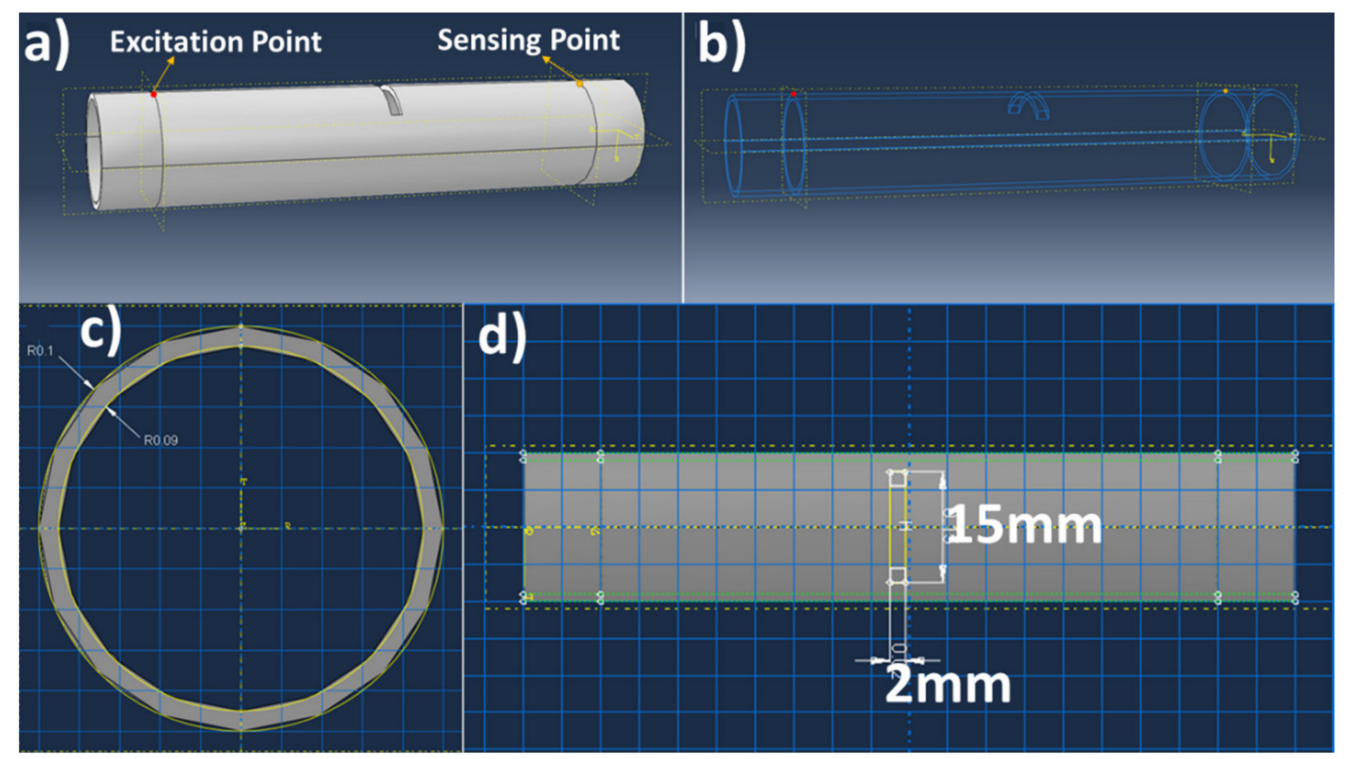

Figure 3. Geometry snapshots of the numerical model designed in Abaqus: (a) cylindrical pipe with partitions visible for excitation and sensing locations, (b) geometry with only edges, (c) sketch of the cylinder radial base, and (d) crack formation and dimensions.

Table 1. Elastic and mechanical properties of steel material in the Abaqus Simulation.

\begin{tabular}{cc}
\hline Property & Value \\
\hline Density & $8207 \mathrm{~kg} / \mathrm{m}^{3}$ \\
\hline Poisson's Ratio & 0.33 \\
\hline Young's Modulus & $129 \mathrm{GPa}$ \\
\hline
\end{tabular}

\subsubsection{Simulation Geometry Variations}

The intensity and speed of sound through a medium depends on characteristics of the medium (such as density, internal material structure such as discontinuity, etc.) but also on environmental conditions, especially temperature. For the purpose of this study, the temperature is kept constant throughout all the simulations, at $25^{\circ} \mathrm{C}$. To study the effects of cracks of multiple sizes and introduction of multiple cracks in the sample, the simulation geometry is introduced with variations, as explained below.

\subsubsection{Different Crack Sizes}

Cracks with length of $15 \mathrm{~mm}$ and width of $4 \mathrm{~mm}$ are introduced at $25 \%, 50 \%$, and $75 \%$ offset location along axis 1 . The simulation response is calculated, and data are generated. After the preprocessing step, the data are compared to their corresponding responses of original crack size simulated earlier.

\subsubsection{Multiple Cracks}

To study the effects of multiple cracks in the steel pipe, an additional crack is added with the original crack at a 50\% offset location. The additional crack's relative location is at $45 \%$ offset along axis 1 . The size of the new crack is $10 \mathrm{~mm}$ in length and $1 \mathrm{~mm}$ in width. The system is simulated with the preset simulation conditions and its response is calculated and data are saved. After the preprocessing step, the data are compared to the system response of a single crack at $50 \%$ offset along axis 1 .

The pipe can be visualized in certain sections based on the crack locations for which simulations are performed, as shown in Figure 4. One crack from the shown cracks is selected at a time for a particular simulation. 


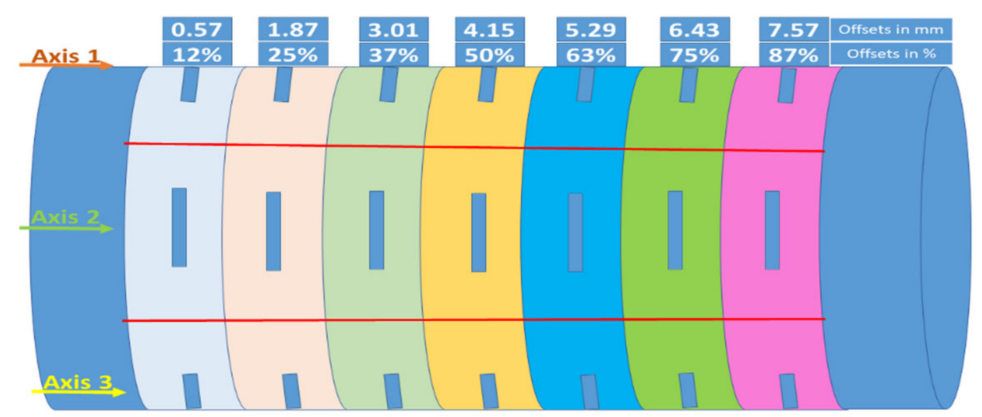

Figure 4. Division of the cylinder in sections corresponding to crack locations.

The labels represent the crack offset in percentage and absolute $(\mathrm{mm})$ values in the horizontal direction from the excitation location. In the vertical direction, the pipe is divided at the boundaries shown by two red horizontal lines in Figure 4, which create three axes: axis 1 , axis 2 , and axis 3 , which may hold a crack. As a result, certain sections can be drawn on the pipe body, which may act as a set of probable damage locations for the estimation algorithm. The corresponding pipe sections are illustrated in Figure 5 . The developed numerical model will enable the operator to output one of these sections as a probable damage location based on the best match with the dataset. To easily identify each crack, a nomenclature is defined (Table 2) that will allocate a unique label to each crack depending upon its location with respect to the axis number, offset percentage, and number of cracks (either single crack or multiple).

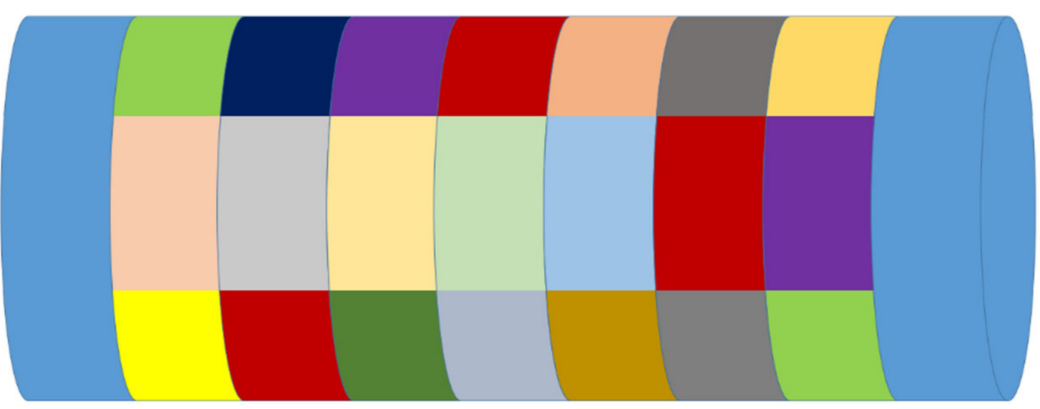

Figure 5. Rectangular regions representing the likely damage-enclosing sections.

Table 2. Nomenclature to uniquely identify each crack.

\begin{tabular}{|c|c|c|c|c|}
\hline \multirow{7}{*}{ A } & \multirow{3}{*}{1} & \multirow{7}{*}{$\mathrm{O}$} & 12 & \multirow{4}{*}{$S$} \\
\hline & & & 25 & \\
\hline & & & 37 & \\
\hline & \multirow{2}{*}{2} & & 50 & \\
\hline & & & 62 & \multirow{3}{*}{$\mathrm{M}$} \\
\hline & \multirow{2}{*}{3} & & 75 & \\
\hline & & & 87 & \\
\hline
\end{tabular}

The crack label is an alphanumeric string of 5 characters, where the first character " $\mathrm{A}$ " stands for axis information, followed by a number 1, 2, or 3 showing the actual axis number in which the crack is located. Afterwards, there is a character " $\mathrm{O}$ " that is about the offset percentage of the crack and is followed by one of the possible offset percentage values, i.e., $12,25,37,50,62,75$, or 87 . Finally, there is a character " $\mathrm{S}$ ", signifying that it is a single crack, or a character " $\mathrm{M}$ " if there are multiple cracks. 


\subsection{Data Acquisition and Preprocessing}

The acquired data are plotted, and a curve-fitting technique is employed to estimate the numerical data model. After observing the data, different mathematical models (polynomial, cubic spline, sinusoidal, composite sinusoidal, exponential, and their combinations, etc.) were employed, and the corresponding fitting errors were observed and analyzed. The results suggest that composite sinusoidal waves have the lowest fitting error, and the corresponding mathematical model is displayed in Equation (3) as follows.

The general data model is represented as:

$$
f(x)=a_{1} * \sin \left(b_{1} * x+c_{1}\right)+a_{2} * \sin \left(b_{2} * x+c_{2}\right),
$$

where function $f$ mathematically indicates the crack response, input parameter $x$ of function $f$ is time, parameters $a_{1}$ and $a_{2}$ are the scaling parameters of sinusoidal functions to model the data, $b_{1}$ and $b_{2}$ are the frequencies of these functions, and $c_{1}$ and $c_{2}$ are the phases of the observed data. The proposed model of the system incorporates 6 free variables $\left(a_{1}, b_{1}, c_{1}\right.$, $a_{2}, b_{2}$, and $\left.c_{2}\right)$, whose values describe the response based on the crack locations. To estimate these parameters in each scenario, the proposed model is reformulated in the form of a cost function $J$, which describes the difference of actual values, $a(x)$, and calculated values by the mathematical model of $f(x)$ :

$$
J=\sum_{n=1}^{N}\left(a(x)-a_{1} * \sin \left(b_{1} * x+c_{1}\right)+a_{2} * \sin \left(b_{2} * x+c_{2}\right)\right)^{2} .
$$

The free variables in the cost function are optimized to minimize the cost function; ideally, $J \approx 0$. This optimization is achieved using any regressive numerical algorithm that minimizes the residual error. For this purpose, an improved version of the simplex algorithm, known as the Nelder-Mead simplex method (NMSM), is used. The operating cycle of the NMSM is based on three steps: ordering, centroid, and transformation [41].

$$
\begin{gathered}
x_{j}=x_{0}+p e_{j}+\sum_{\substack{k=1 \\
k \neq j}}^{n} q e_{k} ; j=1,2, \ldots . ., n, \\
p=\frac{a}{n \sqrt{2}}(\sqrt{n+1}+n-1) \& q=\frac{a}{n \sqrt{2}}(\sqrt{n+1}-1)
\end{gathered}
$$

where $x_{j}(j=1,2, . ., n)$ are the vertices, $x_{0}$ is the initial guess, $n$ is the number of free parameters (6 in this study), and $e_{j}$ is the unit vector in the direction of the $j$ th vertex. The following step is performed to sort the function in ascending order at all vertices:

$$
J\left(x_{l}\right)<J\left(x_{s}\right)<J\left(x_{h}\right) .
$$

where $x_{l}$ is the vertex with the minimum value, $x_{h}$ is the vertex with the maximum value, and $x_{s}$ is the vertex with the second highest value of the cost function. Now, the vertex with the highest value is discarded by defining the centroid:

$$
x=\frac{1}{n} \sum_{\substack{i=0 \\ i \neq h}}^{n} x_{i}
$$

where $x$ is the centroid. The upper bound vertex of the cost function is discarded by reflection, expansion, contraction, and shrinkage. These steps can be mathematically expressed as follows:

$$
\text { Reflection : } x_{r}=x+\delta_{1}\left(x_{h}-x\right)
$$




$$
\begin{gathered}
\text { Expansion : } x_{e}=x+\delta_{2}\left(x_{r}-x\right) \\
\text { Contraction : } x_{c}=x+\delta_{3}\left(x_{e}-x\right) \\
\text { Shrinkage : } x_{s}=x+\delta_{4}\left(x_{c}-x\right)
\end{gathered}
$$

where $\delta 1, \delta 2, \delta 3$, and $\delta 4$ are the reflection, expansion, contraction, and shrinkage coefficients, respectively.

\section{Classification}

Support vector machines (SVMs) are powerful machine learning algorithms wellknown for their superior classification performance. They define such a hyperplane which separates two classes with the largest possible margin. Learning is based on features that best-distinguish the classes during the training phase, and afterwards, SVMs predict the newly presented sample as a member of either of the two classes [42]. The SVM principle is shown in Figure 6.

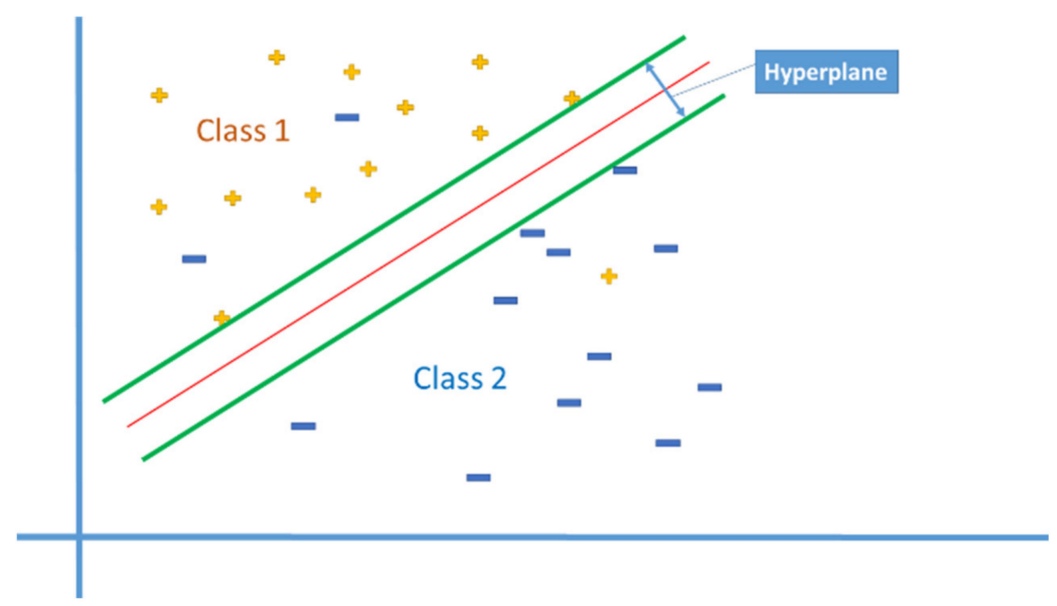

Figure 6. Graphical representation of support vector machine showing the maximum margin hyperplane.

An SVM was designed in MATLAB $^{\circledR}$ and simulation responses were provided to the model. The responses were first divided into a training set ( $70 \%$ of the response dataset) and validation set (30\% of the response dataset). The training set is used in supervised learning of the SVM model based on the feature set. A response is placed in a row of the training matrix, and a corresponding label entry is made in the output vector representing the target class of that input row. Cross-validation was performed using the validation set.

\section{Results and Discussions}

The simulation is repeated by keeping the crack at any of the predefined locations, as depicted in Figure 4, and some additional scenarios are simulated for comparison purposes. Figure 7 displays a comparison of system responses with different crack sizes at an offset of $50 \%$ (A1O50S). The blue waveform is the system response with the original sized crack, whereas the red waveform is the response of the system when simulated with crack width doubled (i.e., width set as $4 \mathrm{~mm}$ ). There is a clear decrease in the amplitude of the received response in case of the bigger crack scenario. Figure 8 represents a comparison of system responses for a single crack and a pair of cracks at an offset of $50 \%$. The waveform represented in blue is the system response with a single crack at $50 \%$ offset location (A1O50S), whereas the red waveform represents the system response when a pair of cracks is introduced around $50 \%$ offset (A1O50M). The exact location of 1 crack is at $45 \%$ offset, and its dimensions are $10 \mathrm{~mm}$ in length and $1 \mathrm{~mm}$ in width. The second crack is at the $50 \%$ offset location with $15 \mathrm{~mm}$ length and $2 \mathrm{~mm}$ width. The comparison clearly shows a decrease in the magnitude of the received wave at sensing points for the case of a two-crack system as compared to the single crack setting. 


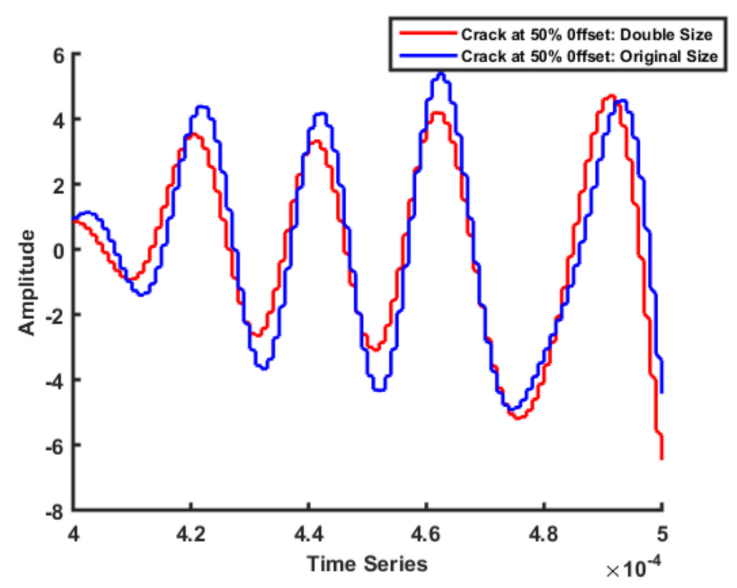

Figure 7. Comparison of system response with an original sized crack and a double sized crack at $50 \%$ offset (A1O50S).

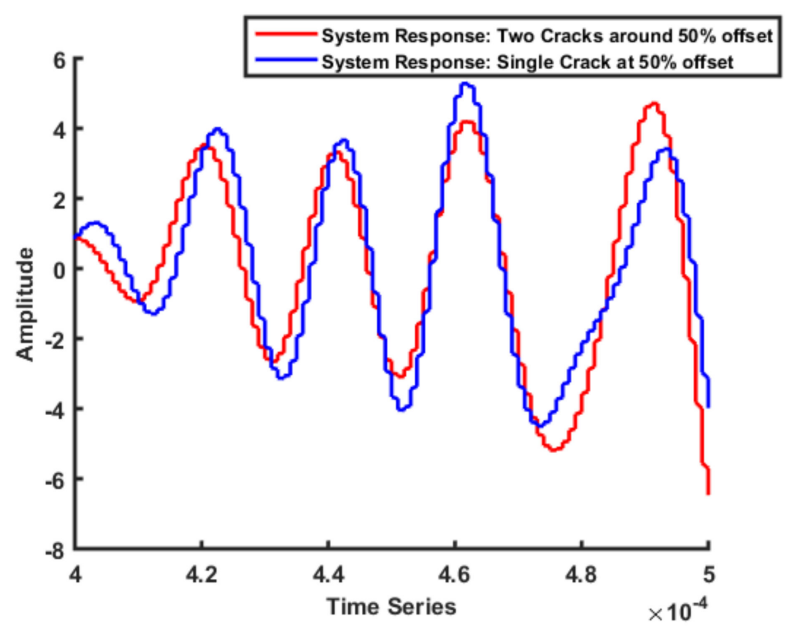

Figure 8. Comparison of system response with a single crack (A1O50S) and a pair of cracks at $50 \%$ offset (A1O50M).

Figure 9 shows the actual and model-fitted waveforms for each crack location along axis 1. Table 3 shows the optimized values and error terms for the amplitudes, frequencies, and phases of the composite sine wave model. Similarly, the process is repeated for the cracks along axis 2. The generated results for that case are shown in Figure 10 and Table 4. In the last step, the process is repeated for the lower edge of the pipe by keeping the crack along axis 3 at different locations. The results of the final case are expressed using Figure 11 and Table 5. The residual error for the actual signal and optimized numerical model is also calculated, and the results are shown in Figures 12 and 13, and in Figure 14 for the cracks along axis 1 , axis 2 , and axis 3 , respectively.

Table 3. Optimized parameters and error terms for the numerical model for the cracks along axis 1.

\begin{tabular}{cccccccc}
\hline $\begin{array}{c}\text { Crack } \\
\text { (Axis 1) }\end{array}$ & Amplitude 1 & $\begin{array}{c}\text { Frequency 1 } \\
\text { KHz }\end{array}$ & Phase 1 & Amplitude 2 & $\begin{array}{c}\text { Frequency 2 } \\
\text { KHz }\end{array}$ & Phase 2 & RMSE \\
\hline $12 \%$ & 1.51 & 298.40 & 8.13 & 0.40 & 247.90 & 1.32 \\
$25 \%$ & 1.58 & 313.80 & -1.53 & 0.54 & 220.70 & 12.95 & 0.32 \\
$37 \%$ & 2.31 & 327.70 & -7.57 & 1.30 & 285.60 & -18.40 & 0.40 \\
$50 \%$ & 3.28 & 262.10 & -7.47 & 1.88 & 216.60 & -9.95 & 1.32 \\
$67 \%$ & 3.81 & 254.40 & -4.32 & 2.53 & 221.10 & -11.99 & 1.68 \\
$75 \%$ & 69.22 & 254.50 & -28.17 & 70.27 & 255.50 & -0.34 & 1.24 \\
$87 \%$ & 1.16 & 331.30 & -9.97 & 1.30 & 278.60 & -9.77 & 0.13 \\
\hline
\end{tabular}




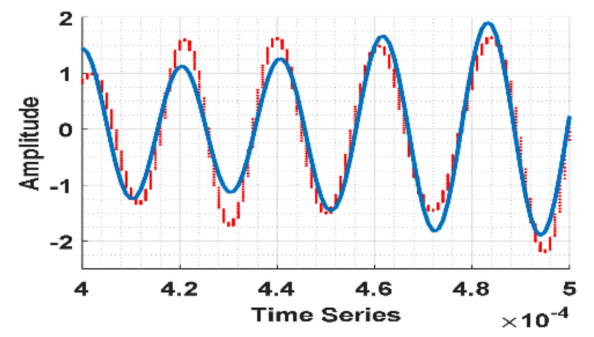

$12 \%$

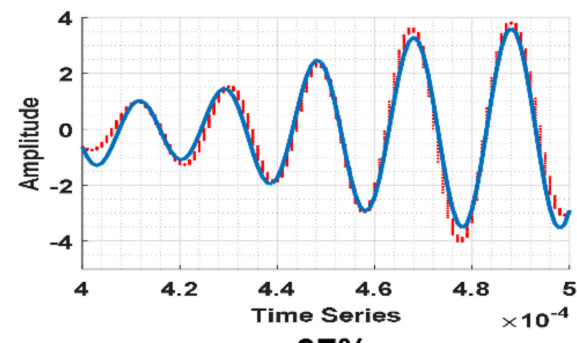

$37 \%$

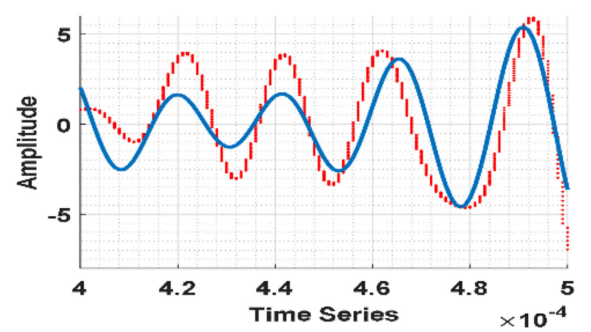

$63 \%$

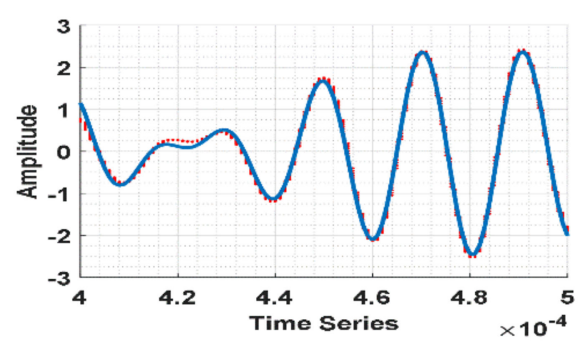

$87 \%$

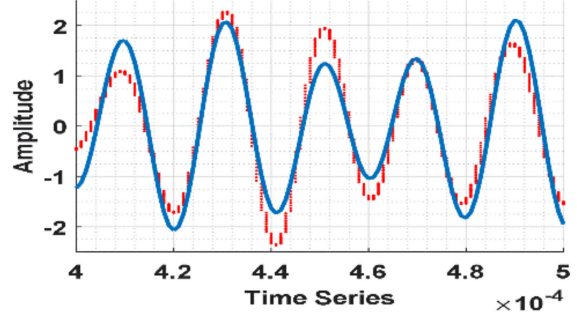

$25 \%$

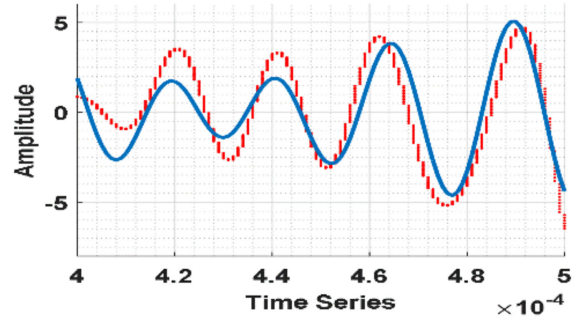

$\mathbf{5 0 \%}$

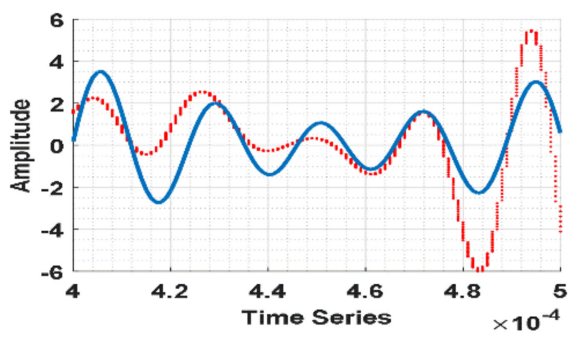

$75 \%$

Original Waveform

Data Fitting Waveform

Figure 9. Comparison of the actual response and optimized mathematical model for the pipe with multiple damage locations indicated via percentage of offset between exciter and sensor locations along axis 1 .

Table 4. Optimized parameters and error terms for the numerical model for the cracks along axis 2.

\begin{tabular}{cccccccc}
\hline $\begin{array}{c}\text { Crack } \\
\text { (Axis 2) }\end{array}$ & Amplitude 1 & $\begin{array}{c}\text { Frequency 1 } \\
\text { KHz }\end{array}$ & Phase 1 & Amplitude 2 & $\begin{array}{c}\text { Frequency 2 } \\
\text { KHz }\end{array}$ & Phase 2 & RMSE \\
\hline $12 \%$ & 37.39 & 295.8 & -17.3 & 36.42 & 300.8 & 2.785 & 1.47 \\
$25 \%$ & 4.47 & 262.00 & -1.92 & 1.41 & 193.70 & -1.11 \\
$37 \%$ & 5.02 & 273.90 & -7.60 & 3.06 & 321.30 & -5.45 & 1.52 \\
$50 \%$ & 4.29 & 303.40 & 7.49 & 1.54 & 221.50 & 13.11 & 1.17 \\
$63 \%$ & 4.21 & 314.00 & 2.70 & 1.31 & 146.70 & -8.49 & 1.19 \\
$75 \%$ & 2301.00 & 295.60 & -16.93 & 2301.00 & 295.60 & 5.04 & 1.53 \\
$87 \%$ & 5.47 & 293.20 & 7.05 & 2.91 & 357.80 & 7.27 \\
\hline
\end{tabular}




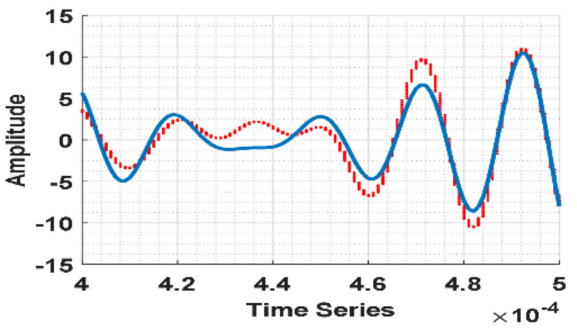

$12 \%$

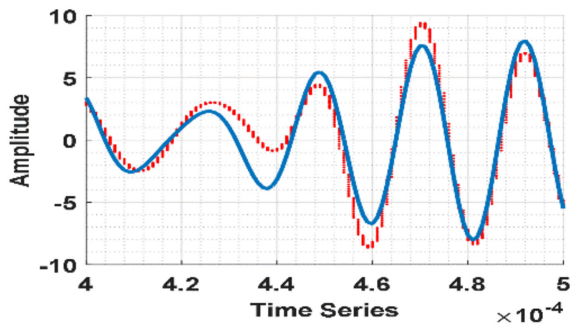

$37 \%$

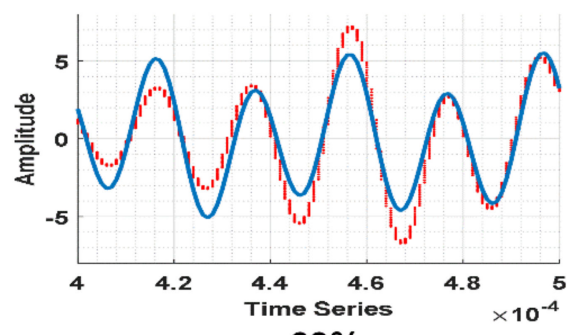

$63 \%$

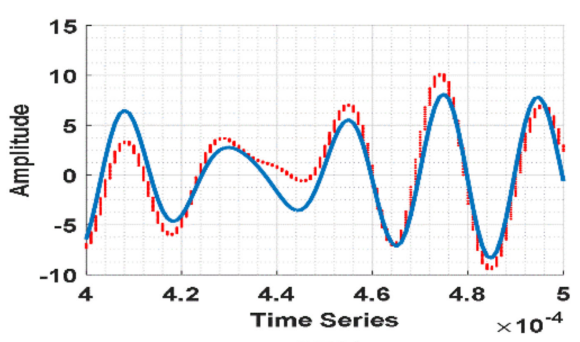

$87 \%$

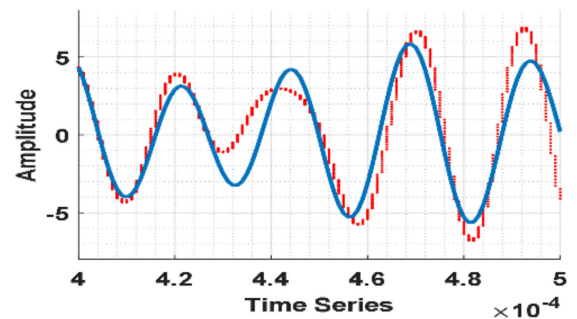

$25 \%$

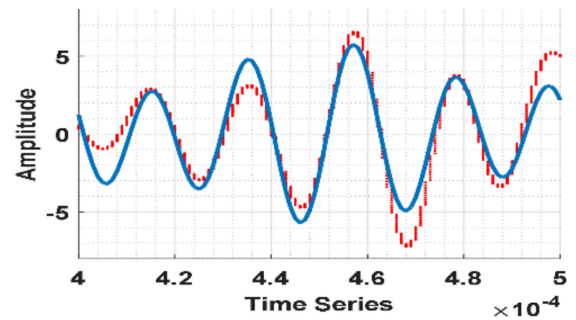

$50 \%$

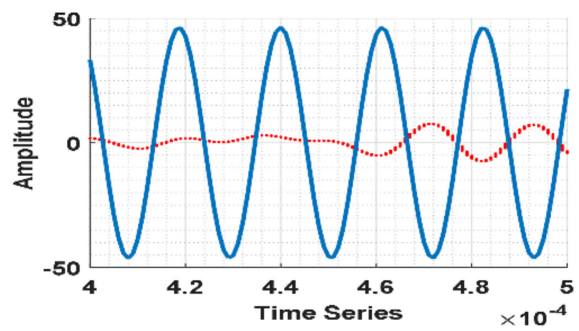

$75 \%$

\section{Original Waveform}

\section{Data Fitting Waveform}

Figure 10. Comparison of the actual response and optimized mathematical model for the pipe with damage in axis 2 .

Table 5. Optimized parameters and error terms for the numerical model for the cracks along axis 3.

\begin{tabular}{cccccccc}
\hline $\begin{array}{c}\text { Crack } \\
\text { (Axis 3) }\end{array}$ & Amplitude 1 & $\begin{array}{c}\text { Frequency 1 } \\
\text { KHz }\end{array}$ & Phase 1 & Amplitude 2 & $\begin{array}{c}\text { Frequency 2 } \\
\text { KHz }\end{array}$ & Phase 2 & RMSE \\
\hline $12 \%$ & 1.94 & 323.90 & -4.05 & 2.33 & 275.80 & -8.29 & 0.47 \\
$25 \%$ & 1.73 & 329.50 & -7.25 & 3.41 & 284.60 & -11.90 & 0.49 \\
$37 \%$ & 2.02 & 282.90 & 13.71 & 2.08 & 350.10 & 15.17 & 0.49 \\
$50 \%$ & 3.22 & 259.70 & -4.42 & 3.20 & 335.10 & -11.60 & 1.47 \\
$63 \%$ & 5.31 & 262.80 & -5.89 & 1.90 & 207.30 & -10.00 & 2.03 \\
$75 \%$ & 2.49 & 361.60 & -20.10 & 7.42 & 279.50 & -9.80 & 1.41 \\
$87 \%$ & 2.76 & 305.00 & 3.53 & 0.40 & 192.30 & 0.28 \\
\hline
\end{tabular}




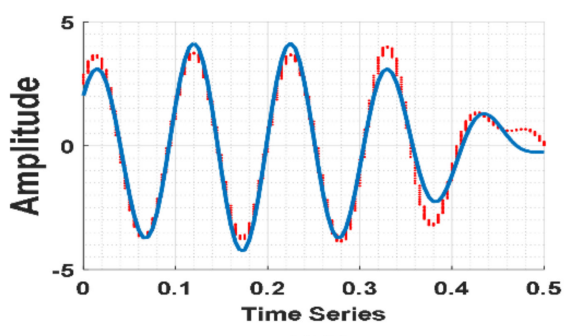

$12 \%$

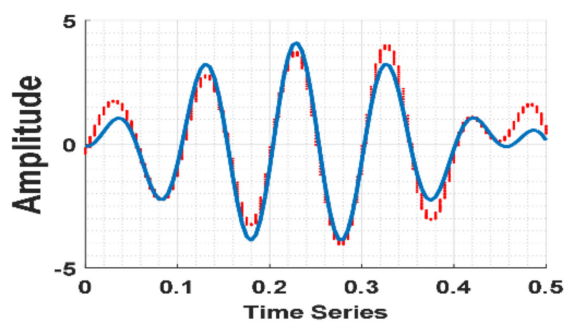

$37 \%$

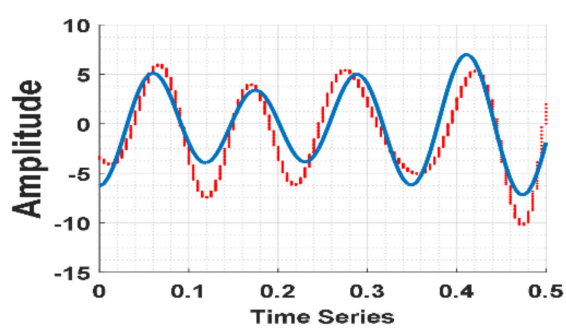

$63 \%$

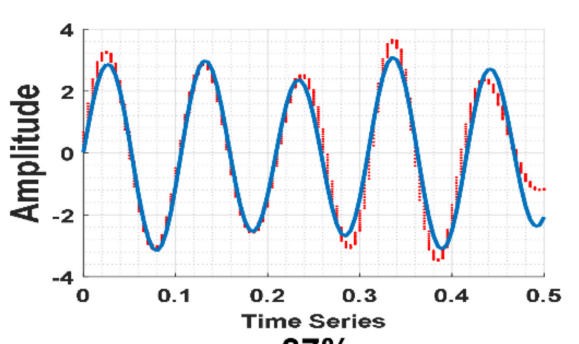

$87 \%$

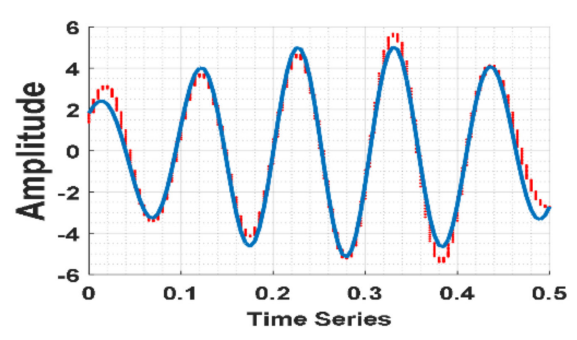

$25 \%$

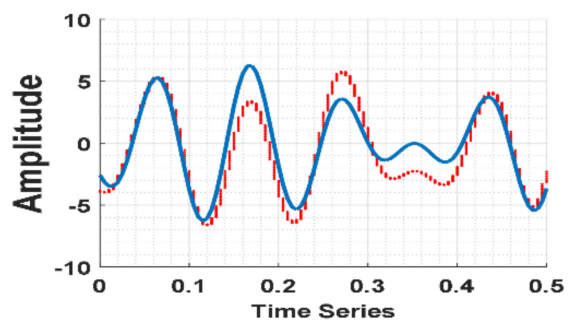

$50 \%$

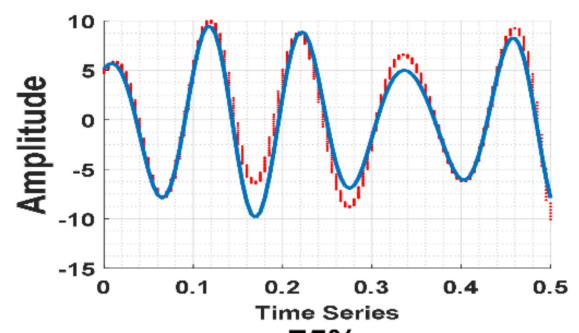

$75 \%$

\section{Original Waveform}

\section{Data Fitting Waveform}

Figure 11. Comparison of the actual response and optimized mathematical model for the pipe with damage in axis 3 .

SVM was used to classify the pipe models in two possible categories, i.e., pipes with crack and pipes without a crack. The test dataset was applied to the designed SVM model without presenting the output data label corresponding to the particular response. The predicted output label of SVM was compared to the actual output label of each response and the prediction accuracy of the developed model resulted as $87 \%$.

Photoacoustic imaging (PAI) is a rapidly emerging, nondestructive imaging tool to detect metal defects, which can visualize multiple types of cracks. There have been studies on the detection of multi-scale damage in carbon fiber-reinforced plastic (CFRP) composites with ultrahigh-resolution detection [43]. Studies employing finite element model simulations of a structure with micro-cracks study the interaction of the microcracks with Lamb waves. The results indicate that the micro-cracks lead to the generation of second harmonics [44]. 


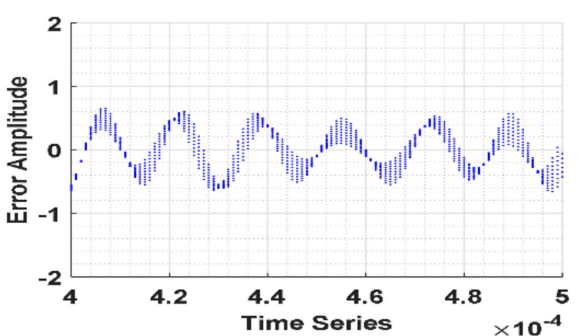

$12 \%$

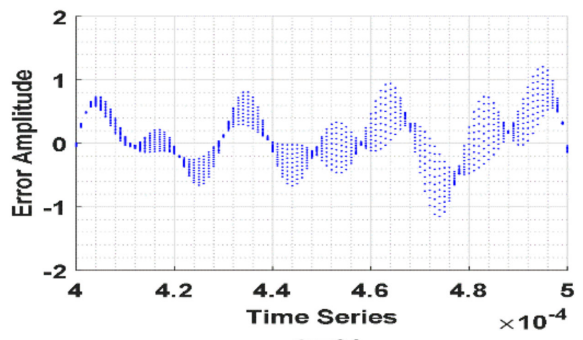

$37 \%$

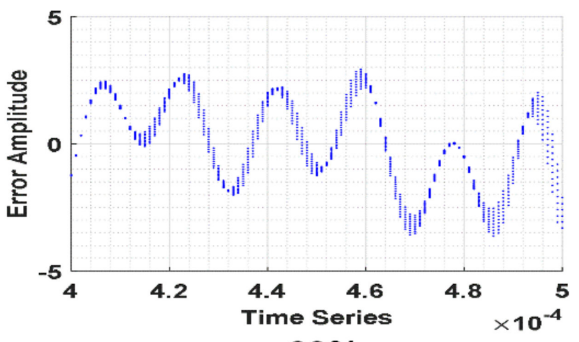

$63 \%$

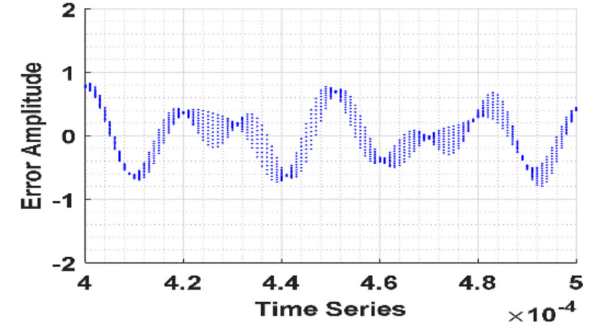

$25 \%$

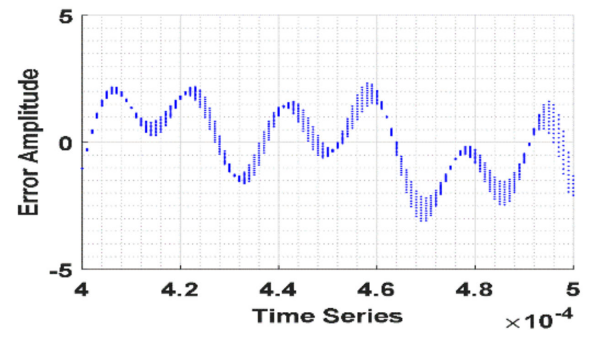

$50 \%$

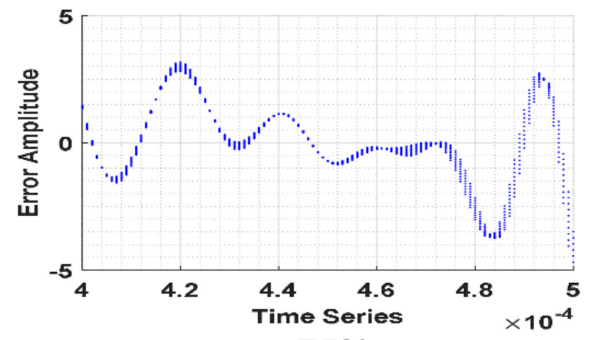

$75 \%$

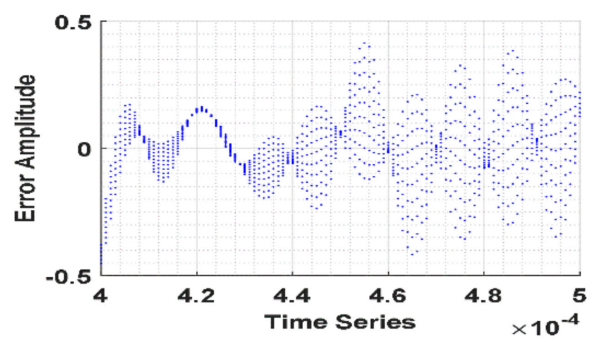

$87 \%$

Figure 12. Residual error of the actual signal and model results for cracks at axis 1 .

For internal defect detection, some studies extract and combine spatial and temporal features to estimate the physical properties such as Young's modulus [45]. Previous studies also suggest that faults can be detected by estimation of absolute acoustic nonlinearity parameter, beta, defined by the displacement amplitudes of the fundamental and secondorder harmonic frequency components of the ultrasonic wave propagating through the material [46]. This study analyzed the effects of cracks in a steel pipe and their location on the properties of acoustic waves that travel through it. Figures 7-14 and Tables 3-5 present the results of this study. Figure 9 displays the actual response of the system and its corresponding numerical model for damage locations along the axis of wave propagation. There is a figure for each system response and its optimized model for damage at offsets of $12 \%, 25 \%, 37 \%, 50 \%, 63 \%, 75 \%$, and $87 \%$ along the wave propagation axis, i.e., axis 1 . The black curve is the actual data curve of the system, and the blue series is the numerical model curve. 


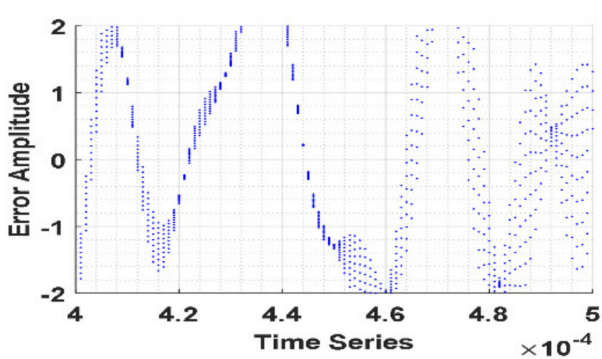

$12 \%$
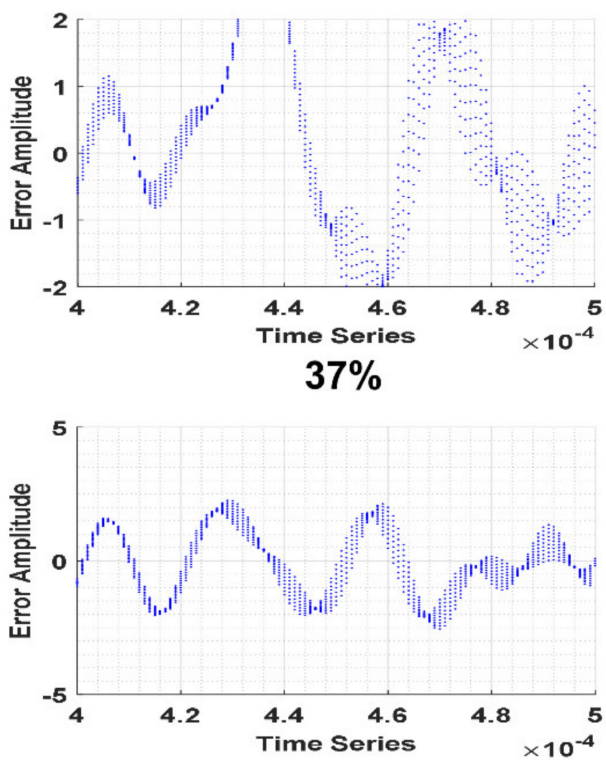

$63 \%$

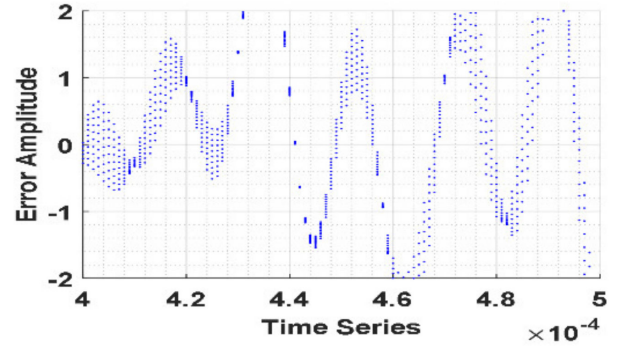

$25 \%$
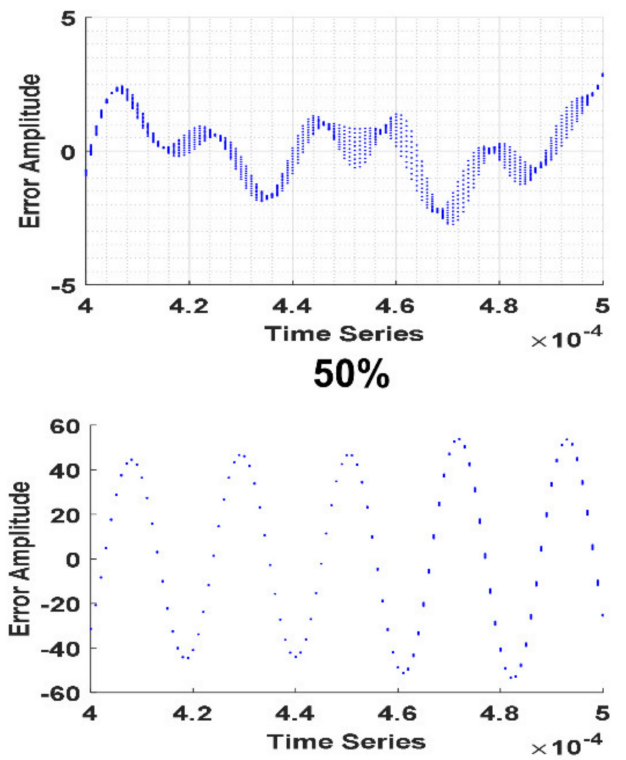

$75 \%$

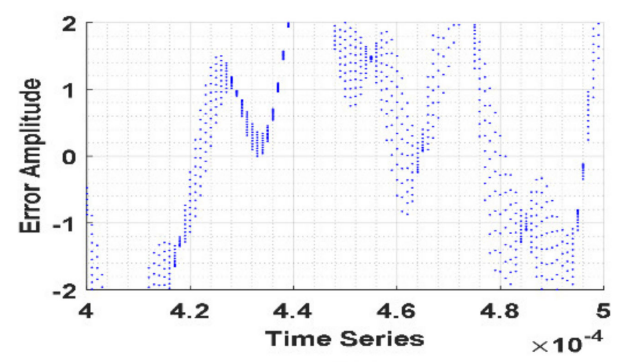

$87 \%$

Figure 13. Residual error of the actual signal and model results for cracks at axis 2.

There is quite good fit at most points, except on a few occasions, where there are small differences, although the differences are within a permissible tolerance limit. Table 3 shows optimized parameters and root mean square error (RMSE) for the wave propagating with cracks along axis 1 . These parameters include amplitudes, frequencies, and phases for both sine components of the composite sine wave numerical model. The results of the study are consistent with previous studies that show that the non-linear components of ultrasonic waves generated by frequency mixing can be utilized to detect micro-cracks in metals [47]. Similarly, Figure 10 and Table 4 show the results for the system with cracks at locations along the axis at $90^{\circ}$ from the wave propagation axis, i.e., axis 2 . Finally, Figure 11 and Table 5 show the results for crack locations on the opposite edge axis of the wave propagation axis, i.e., axis 3 . Figure 12 plots the residual error that occurs among the actual and numerical series for each crack location along the wave propagation axis, axis 1 . The residuals appear randomly scattered around zero, which shows that our numerical model is a good fit to the actual simulation data. Figures 13 and 14 show the residual error plots for cracks along axis 2 and axis 3, respectively. 


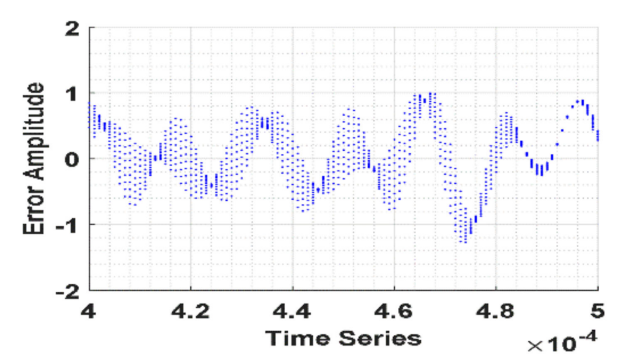

$12 \%$

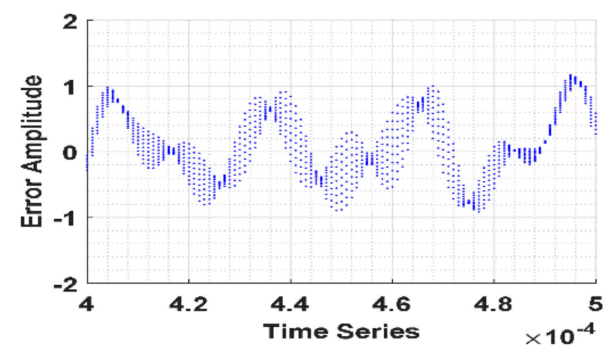

$37 \%$

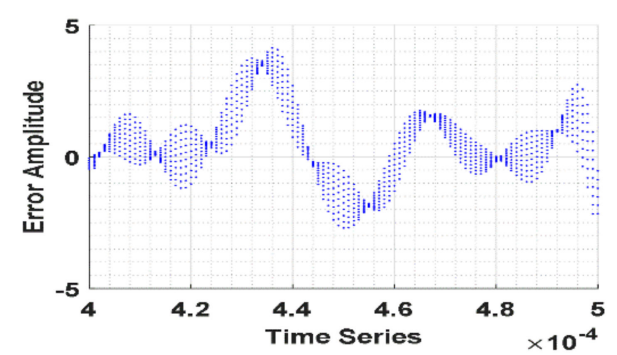

$63 \%$

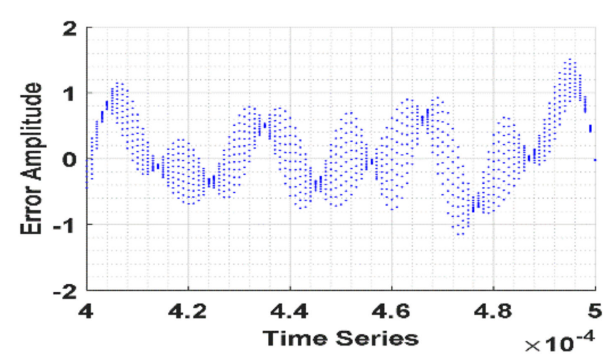

$25 \%$

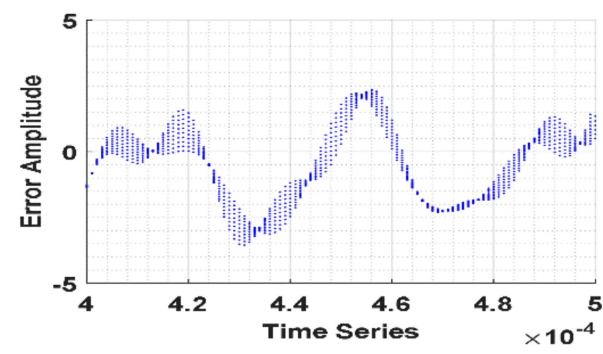

$50 \%$

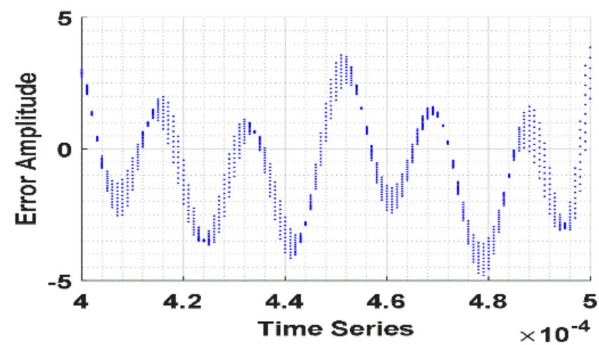

$75 \%$

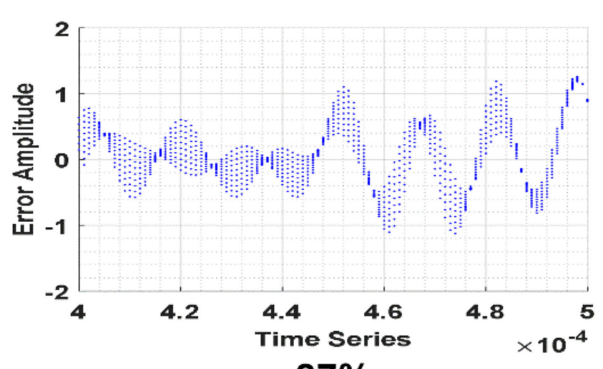

$87 \%$

Figure 14. Residual error of the actual signal and model results for cracks along axis 3.

By increasing the simulation data with more damage locations, this output area can always be minimized, and more precision can be introduced.

\section{Conclusions}

This study aimed to explore the effects of the internal steel structures on acoustic waves traveling through them and provide a baseline study for future research to accurately and precisely locate a crack/damage in steel. The basic idea is that the internal structure of metal and steel in this case may change the propagating wave parameters, such as the frequency, amplitude, and phase. This difference in wave parameters corresponding to certain damage locations enabled us to devise a damage estimation mechanism for an unknown crack location response. The results of this study evaluated and compared the response of the system under varying damage locations. In the future, the findings of this study will be enhanced to develop a model to relate certain wave parameters with particular damage locations. 
Author Contributions: A.A. designed and performed the simulations. He collected simulation data, prepared the figures, and wrote the manuscript; M.A.K. analyzed the data and performed the data fitting procedures; M.Y.J. and J.K. conceived and supervised the project. All authors contributed to the critical reading and writing of the manuscript. All authors have read and agreed to the published version of the manuscript.

Funding: This work was supported by the National Research Foundation of Korea (NRF) granted by the Korean government (MSIT) (No. 2017R1A2B2006999) and supported by the Ministry of Trade, Industry and Energy (Grant N0002310).

Institutional Review Board Statement: Not applicable.

Informed Consent Statement: Not applicable.

Conflicts of Interest: The authors declare no conflict of interest.

\section{References}

1. Hou, B.; Li, X.; Ma, X.; Du, C.; Zhang, D.; Zheng, M.; Xu, W.; Lu, D.; Ma, F. The cost of corrosion in China. npj Mater. Degrad. 2017, 1,1-10. [CrossRef]

2. Flint, G.; Packirisamy, S.J. Purity of food cooked in stainless steel utensils. Food Addit. Contam. 1997, 14, 115-126. [CrossRef]

3. Liu, Q.; Zhu, Y.; Yuan, X.; Zhang, J.; Wu, R.; Dou, Q.; Liu, S. Internet of Things Health Detection System in Steel Structure Construction Management. IEEE Access 2020, 8, 147162-147172. [CrossRef]

4. Lo, K.H.; Shek, C.H.; Lai, J.K.L. Recent developments in stainless steels. Mater. Sci. Eng. R Rep. 2009, 65, 39-104. [CrossRef]

5. Baddoo, N.R. Stainless steel in construction: A review of research, applications, challenges and opportunities. J. Constr. Steel Res. 2008, 64, 1199-1206. [CrossRef]

6. Oluwasola, E.A.; Hainin, M.R.; Aziz, M.M.A. Characteristics and utilization of steel slag in road construction. Jurnal Teknologi 2014, 70, 117-123. [CrossRef]

7. Kerouedan, J.; Queffelec, P.; Talbot, P.; Quendo, C.; De Blasi, S.; Le Brun, A. Detection of micro-cracks on metal surfaces using near-field microwave dual-behavior resonator filters. Meas. Sci. Technol. 2008, 19, 105701. [CrossRef]

8. Lankford, J.; Kusenberger, F.J. Initiation of fatigue cracks in 4340 steel. Metall. Trans. 1973, 4, 553-559. [CrossRef]

9. Liu, S.; Chai, K.; Zhang, C.; Jin, L.; Yang, Q.J. Electromagnetic Acoustic Detection of Steel Plate Defects Based on High-Energy Pulse Excitation. Appl. Sci. 2020, 10, 5534. [CrossRef]

10. Otegui, J.; Kerr, H.; Burns, D.; Mohaupt, U.J. Fatigue crack initiation from defects at weld toes in steel. Int. J. Press. Vessel. Pip. 1989, 38, 385-417. [CrossRef]

11. Rajan, K.; Narasimhan, K.J. An investigation of the development of defects during flow forming of high strength thin wall steel tubes. Pract. Fail. Anal. 2001, 1, 69-76. [CrossRef]

12. Soukup, D.; Huber-Mörk, R. Convolutional neural networks for steel surface defect detection from photometric stereo images. In International Symposium on Visual Computing; Springer: Cham, Switzerland, 2014; pp. 668-677.

13. ASCE. 2021 Report Card for America's Infrastructure. American Society of Civil Engineers: Reston, VA, USA, 2021. Available online: https:/ / infrastructurereportcard.org/wp-content/uploads/2020/12/2021-IRC-Executive-Summary-1.pdf (accessed on 25 June 2021).

14. Geng, J.; Sun, Q.; Zhang, Y.; Cao, L.; Zhang, W. Studying the dynamic damage failure of concrete based on acoustic emission. Constr. Build. Mater. 2017, 149, 9-16. [CrossRef]

15. Gholizadeh, S. A review of non-destructive testing methods of composite materials. Procedia Struct. Integr. 2016, 1, 50-57. [CrossRef]

16. Shah, S.G.; Kishen, J.C. Use of acoustic emissions in flexural fatigue crack growth studies on concrete. Eng. Fract. Mech. 2012, 87, 36-47. [CrossRef]

17. Ramani, V.; Kuang, K.S.C. Monitoring chloride ingress in concrete using an imaging probe sensor with sacrificial metal foil. Autom. Constr. 2020, 117, 103260. [CrossRef]

18. Schlichting, J.; Maierhofer, C.; Kreutzbruck, M.; International, E. Crack sizing by laser excited thermography. NDT E Int. 2012, 45, 133-140. [CrossRef]

19. Xu, Y.; Li, S.; Zhang, D.; Jin, Y.; Zhang, F.; Li, N.; Li, H. Identification framework for cracks on a steel structure surface by a restricted Boltzmann machines algorithm based on consumer-grade camera images. Struct. Control. Health Monit. 2018, 25, e2075. [CrossRef]

20. Wang, N.; Zhao, Q.; Li, S.; Zhao, X.; Zhao, P. Damage classification for masonry historic structures using convolutional neural networks based on still images. Comput. Aided Civ. Infrastruct. Eng. 2018, 33, 1073-1089. [CrossRef]

21. Carden, E.P.; Fanning, P. Vibration based condition monitoring: A review. Struct. Health Monit. 2004, 3, 355-377. [CrossRef]

22. Khan, A.; Stanbridge, A.B.; Ewins, D.J. Detecting damage in vibrating structures with a scanning LDV. Opt. Lasers Eng. 1999, 32, 583-592. [CrossRef]

23. Walker, S.V.; Kim, J.-Y.; Qu, J.; Jacobs, L.J. Fatigue damage evaluation in A36 steel using nonlinear Rayleigh surface waves. NDT E Int. 2012, 48, 10-15. [CrossRef] 
24. Sagar, S.P.; Parida, N.; Das, S.; Dobmann, G.; Bhattacharya, D.K. Magnetic Barkhausen emission to evaluate fatigue damage in a low carbon structural steel. Int. J. Fatigue 2005, 27, 317-322. [CrossRef]

25. Chang, Y.; Jiao, J.; Liu, X.; Li, G.; He, C.; Wu, B. Nondestructive evaluation of fatigue in ferromagnetic material using magnetic frequency mixing technology. NDT E Int. 2020, 111, 102209. [CrossRef]

26. Man, J.; Vystavěl, T.; Weidner, A.; Kuběna, I.; Petrenec, M.; Kruml, T.; Polák, J. Study of cyclic strain localization and fatigue crack initiation using FIB technique. Int. J. Fatigue 2012, 39, 44-53. [CrossRef]

27. Ding, X.; Li, W.; Xiong, J.; Shen, Y.; Huang, W. A flexible laser ultrasound transducer for Lamb wave based structural health monitoring. Smart Mater. Struct. 2020, 29, 075006. [CrossRef]

28. Kim, Y.-M.; Han, G.; Kim, H.; Oh, T.-M.; Kim, J.-S.; Kwon, T.-H. An Integrated Approach to Real-Time Acoustic Emission Damage Source Localization in Piled Raft Foundations. Appl. Sci. 2020, 10, 8727. [CrossRef]

29. Naeimi, M.; Li, Z.; Qian, Z.; Zhou, Y.; Wu, J.; Petrov, R.H.; Sietsma, J.; Dollevoet, R. Reconstruction of the rolling contact fatigue cracks in rails using X-ray computed tomography. NDT E Int. 2017, 92, 199-212. [CrossRef]

30. Wang, R.; Liu, F.; Hou, F.; Jiang, W.; Hou, Q.; Yu, L. A non-contact fault diagnosis method for rolling bearings based on acoustic imaging and convolutional neural networks. IEEE Access 2020, 8, 132761-132774. [CrossRef]

31. Guldur, B.; Yan, Y.; Hajjar, J.F. Condition assessment of bridges using terrestrial laser scanners. In Structures Congress; American Society of Civil Engineers: Reston, VA, USA, 2015; pp. 355-366.

32. Rucka, M.; Zima, B.; Kędra, R. Application of guided wave propagation in diagnostics of steel bridge components. Arch. Civ. Eng. 2014, 60, 493-516. [CrossRef]

33. Park, D.-G.; Angani, C.S.; Rao, B.; Vértesy, G.; Lee, D.-H.; Kim, K.-H. Detection of the subsurface cracks in a stainless steel plate using pulsed eddy current. J. Nondestruct. Eval. 2013, 32, 350-353. [CrossRef]

34. Knitter-Piątkowska, A.; Dobrzycki, A. Application of Wavelet Transform to Damage Identification in the Steel Structure Elements. Appl. Sci. 2020, 10, 8198. [CrossRef]

35. Tang, S.; Wang, R.; Han, J. Acoustic Focusing Imaging Characteristics Based on Double Negative Locally Resonant Phononic Crystal. IEEE Access 2019, 7, 112598-112604. [CrossRef]

36. Billeh, Y.N.; Liu, M.; Buma, T. Spectroscopic photoacoustic microscopy using a photonic crystal fiber supercontinuum source. Opt. Express 2010, 18, 18519-18524. [CrossRef] [PubMed]

37. Granchi, S.; Vannacci, E.; Miris, L.; Onofri, L.; Zingoni, D.; Biagi, E. Spectral Analysis of Ultrasonic and Photo Acoustic Signals Generated by a Prototypal Fiber Microprobe for Media Characterization. Sens. Imaging 2020, 21, 1-13. [CrossRef]

38. Minonzio, J.-G.; Cataldo, B.; Olivares, R.; Ramiandrisoa, D.; Soto, R.; Crawford, B.; De Albuquerque, V.H.C.; Munoz, R. Automatic Classifying of Patients with Non-Traumatic Fractures Based on Ultrasonic Guided Wave Spectrum Image Using a Dynamic Support Vector Machine. IEEE Access 2020, 8, 194752-194764. [CrossRef]

39. Fitzpatrick, A.; Singhvi, A.; Arbabian, A. An Airborne Sonar System for Underwater Remote Sensing and Imaging. IEEE Access 2020, 8, 189945-189959. [CrossRef]

40. Liu, P.; Sohn, H. Numerical simulation of damage detection using laser-generated ultrasound. Ultrasonics 2016, 69, 248-258. [CrossRef]

41. Kamran, M.A.; Jeong, M.Y.; Mannan, M. Optimal hemodynamic response model for functional near-infrared spectroscopy. Front. Behav. Neurosci. 2015, 9, 151. [CrossRef]

42. Gong, L.; Yu, X.; Wang, J. Curve-Localizability-SVM Active Localization Research for Mobile Robots in Outdoor Environments. Appl. Sci. 2021, 11, 4362. [CrossRef]

43. Wang, S.; Echeverry, J.; Trevisi, L.; Prather, K.; Xiang, L.; Liu, Y. Ultrahigh resolution pulsed laser-induced photoacoustic detection of multi-scale damage in CFRP composites. Appl. Sci. 2020, 10, 2106. [CrossRef]

44. Li, X.; Shui, G.; Zhao, Y.; Wang, Y.-S. Propagation of Non-Linear Lamb Waves in Adhesive Joint with Micro-Cracks Distributing Randomly. Appl. Sci. 2020, 10, 741. [CrossRef]

45. Kazys, R.J.; Mazeika, L.; Sestoke, J. Development of ultrasonic techniques for measurement of spatially non-uniform elastic properties of thin plates by means of a guided sub-sonic A0 mode. Appl. Sci. 2020, 10, 3299. [CrossRef]

46. Park, S.-H.; Kim, J.; Song, D.-G.; Choi, S.; Jhang, K.-Y. Measurement of Absolute Acoustic Nonlinearity Parameter Using Laser-Ultrasonic Detection. Appl. Sci. 2021, 11, 4175. [CrossRef]

47. Guan, L.; Zou, M.; Wan, X.; Li, Y. Nonlinear Lamb wave micro-crack direction identification in plates with mixed-frequency technique. Appl. Sci. 2020, 10, 2135. [CrossRef] 